\title{
Comportamento da Mosca Doméstica, Musca domestica L., em Relação ao Uso de Saco Plástico Transparente Contendo Água
}

\author{
Anderson D. Grützmacher ${ }^{1}$ e Octávio Nakano ${ }^{2}$ \\ ${ }^{1}$ Departamento de Fitossanidade, FAEM/UFPel, Caixa postal 354, 96.010-900, Pelotas, RS. \\ ${ }^{2}$ Departamento de Entomologia, ESALQ/USP, Caixa postal 09, 13.418-900, Piracicaba, SP.
}

An. Soc. Entomol. Brasil 26(3): 455-461 (1997)

\begin{abstract}
Behavior of House Fly, Musca domestica L., in Relation to Transparent Plastic Bags with Water
\end{abstract}

\begin{abstract}
The behavior of the house fly, Musca domestica L., was studied in relation to the effect of transparent plastic bags with water, using a black light (BL) and black light blue (BLB) ultraviolet lamps in a light testator in a dark room. The house fly used in the tests were from laboratory colony. In an additional test plastic bags containing water coloured with yellow, red and green aniline, and with air only were compared. The greatest housefly capture occurred with black light lamps (BL). In relation to the tests with coloured water, yellow was the most attractive and green the least attractive color. Transparent plastic bag with water showed repellency to the house fly greater than $30 \%$.
\end{abstract}

KEY WORDS: Insecta, Diptera, ultraviolet lamps, light, coloured water, repellent.

RESUMO - Estudou-se o comportamento da Musca domestica L. em relação ao efeito repelente do saco plástico transparente contendo água, utilizando lâmpadas ultravioleta BL (luz negra) e BLB (luz negra azul) em um testador de luz em sala escura, com moscas domésticas criadas em laboratório. Em outro experimento utilizaram-se sacos plásticos transparentes contendo água colorida com anilina amarela, vermelha e verde, e um tratamento adicional com saco plástico transparente contendo somente ar. No teste realizado com lâmpadas ultravioleta as maiores coletas foram com lâmpadas de luz negra (BL). Em relação aos testes com água colorida, a amarela foi a mais atrativa e a verde a menos atrativa. O saco plástico transparente contendo água mostrou em média eficiência superior a $30 \%$ em repelir a mosca doméstica.

PALAVRAS-CHAVE: Insecta, Diptera, lâmpadas ultravioleta, luz, água colorida, repelência.

A mosca doméstica, Musca domestica L., é uma espécie cosmopolita. Sua dispersão e distribuição pelo mundo foi favorecida por ter a capacidade de se adaptar às transformações do ambiente natural e proliferar tanto no meio urbano quanto no meio rural. Nas cidades, infesta residências e locais de trabalho, causando incômodos e danos para à população. O problema com moscas vem aumentando nos últimos 10 anos 
com tendência a se agravar (Guimarães 1985).

Os produtos químicos utilizados no controle das moscas têm sido ineficazes. Em decorrência da alta capacidade reprodutiva, seu uso constante tem proporcionado o aparecimento de indivíduos resistentes, além de contaminar alimentos como ovos e carnes. Alguns inseticidas já deixaram de ser empregados, a exemplo do DDT (Mello \& Pigatti 1961), e do dimetoato (Suplicy et al. 1972), pois tornaram-se ineficientes devido ao aparecimento de raças resistentes aos mesmos. Sabe-se que um controle satisfatório, sempre é obtido com um programa que integra métodos culturais, químicos e biológicos.

Deay \& Taylor (1962) tem-se preocupado em estudar o comportamento da mosca doméstica em relação à sua atratividade por lâmpadas de diferentes comprimentos de onda, o que permitiu o desenvolvimento de armadilhas luminosas por Thimijan et al. (1970). Pickens et al. (1969) estudaram a resposta da mosca doméstica à lâmpadas fluorescentes, bem como a influência da idade, nutrição da mosca, temperatura do ar e a posição das lâmpadas. Verificaram que as lâmpadas fluorescentes de luz negra (BL) e luz negra azul (BLB), a uma altura de $2 \mathrm{~m}$, foram mais atrativas para mosca doméstica em estábulos, e que os machos foram os mais atraidos. Do mesmo modo, Botelho et al. (1973) testaram o efeito de seis lâmpadas fluorescentes de diversas cores, na atração de M. domestica e observaram uma maior atração pelas lâmpadas BL e BLB. Burg \& Axtell (1984) observaram que em um aviário com gaiolas suspensas as armadilhas de cor amarela coletaram mais mosca do que as de cor vermelha, verde, azul, preta e branca. Pickens \& Thimijan (1986) concluiram que o brilho e o tamanho, tendo como objetivo o ultravioleta, foram os dois parâmetros mais importantes que influenciaram na captura da mosca doméstica por armadilhas elétricas. Rutz et al. (1988) analisaram a eficiência do esquema da eletrocussão em moscas combinado com a atração com luz negra, em aviários, bem como o efeito do atraente muscalure (Z-9-tricosene), o qual aumentou a mortalidade das moscas em ca. $76 \%$. De modo similar, Pickens (1989) estudou a combinação de bulbos fluorescentes com luz negra (BL) e luz negra azul (BLB) quando associados com uma armadilha de eletrocussão para mosca doméstica. As combinações dos bulbos de BL e BLB não foram mais atraentes para mosca doméstica do que o uso de bulbos de BL usados isoladamente.

A maioria dos trabalhos na literatura refere-se a experimentos realizados com armadilhas contendo lâmpadas ultravioletas ou com o uso de iscas. Não há referências ao comportamento da mosca doméstica, em relação ao uso do saco plástico contendo água e a influência da luz sobre esse saco plástico na repelência da mosca. O objetivo do trabalho foi avaliar o comportamento da $M$. domestica em relação ao uso destes sacos plásticos transparentes com água associado ao efeito da luz.

\section{Material e Métodos}

O experimento foi realizado no Departamento de Entomologia da ESALQ/USP, Piracicaba - SP, de agosto a novembro de 1995, com insetos oriundos de uma criação existente no laboratório. Para os testes com lâmpadas, realizado em sala escura, foi utilizado um testador de ferro galvanizado hexagonal, com tubos $(15 \times 64 \mathrm{~cm})$ em cada face. As moscas foram colocadas na parte central e nas extremidades dos tubos foram utilizados dois tipos de tampas: uma de vidro e outra de metal. As entradas para os tubos foram fechadas com vidros para impedir que os insetos deixassem a parte central, antes do início do teste. Nas aberturas externas dos tubos foram colocados sacos plásticos transparentes presos por elásticos e próximo a estes (10 cm no tubo) tampados com chapas de metal. Os sacos plásticos (8 x $24 \mathrm{~cm})$ contendo $150 \mathrm{ml}$ de água foram pendurados a $5 \mathrm{~cm}$ frente aos tubos.

As moscas em número de 500 para cada liberação foram colocadas no congelador por 
10 min. sendo imediatamente colocadas na parte central do aparelho. Os vidros que impediam a entrada para os tubos foram mantidos fechados, com a tampa metálica próxima à extremidade mantida aberta e as luzes acesas. Cinco minutos após a colocação dos insetos, as tampas de vidro foram abertas. Depois de uma hora as chapas metálicas próximas às extremidades foram colocadas para aprisionar os insetos que haviam sido atraídos, para os sacos plásticos $(25 \times 35 \mathrm{~cm})$. Os insetos foram mortos com éter sulfúrico e contados, tanto os atraídos como os mortos e os que permaneceram na parte central do equipamento. Em cada liberação a posição das lâmpadas foi trocada. Foram feitas um total de quatro liberações, sendo utilizadas cinco repetições para cada disposição das lâmpadas. Foram testadas duas lâmpadas do modelo $\mathrm{F}_{15} \mathrm{~T}_{8}$ com as seguintes especificações: BL (luz negra ultravioleta) e BLB (luz negra azul ultravioleta). O delineamento estatístico adotado foi o de blocos casualizados.

O mesmo teste foi realizado no campo, sem o uso das lâmpadas, sendo as liberações feitas à sombra. Avaliou-se a influência de sacos plásticos transparentes contendo água colorida por anilina amarela, vermelha e verde, comparados com saco plástico transparente contendo água e de saco plástico com somente ar. Os dados das contagens das moscas capturadas foram submetidos à análise de variância e as médias comparadas pelo teste de Duncan $(\mathrm{P} \leq 0,05)$.

Também foram feitos testes com três caixas $(0,5 \times 0,5 \mathrm{~m})$, em uma sala $(3 \times 3 \mathrm{~m})$, onde se realizaram diferentes tratamentos utilizando uma testemunha e uma caixa com saco plástico transparente $(12 \times 26 \mathrm{~cm}) \mathrm{com}$ $500 \mathrm{ml}$ de água. O saco plástico contendo água foi colocado na frente da abertura de cada caixa nos diferentes tratamentos, simulando o interior de um recinto. Em cada liberação na sala foram utilizadas em torno de 500 moscas. Em um outro tratamento foi utilizado um espelho $(8 \times 12 \mathrm{~cm})$, também colocado na frente da caixa. Do mesmo modo, também foram utilizados sacos plásticos transparentes contendo água colorida com anilina amarela, vermelha e verde, utilizando para todas as cores 30 gotas de anilina. Dentro das caixas foi colocado o atraente Moscafim, que contém Metomil 90\% (pó solúvel), Muscamone ${ }^{\circledR}$ (60\% Z-9-tricosene), Bitrex e ingredientes inertes. A dose recomendada é de $2 \mathrm{gr} / \mathrm{m}^{2}$, mas foi utilizado o dobro para comprovar a repelência do saco plástico contendo água. Para comparar a eficiência dos diferentes tratamentos foi usada a fórmula de Abbott segundo Nakano et al. (1981).

\section{Resultados e Discussão}

Foi obtida uma maior coleta de moscas domésticas com as lâmpadas BL (Tabela 1), diferindo estatisticamente no tratamento com saco plástico contendo água. Em relação ao saco plástico transparente contendo água colocado na boca do cano antes da luz, este se mostrou repelente, coletando em média $31,9 \%$ do total das moscas liberadas (Tabela 1), diferindo significativamente do tratamento sem saco plástico. Nos tratamentos onde não se utilizou o saco plástico transparente com água foram observadas as maiores coletas de moscas.

Foram utilizadas as lâmpadas BL e BLB porque segundo Botelho et al. (1973) são as mais atrativas para mosca doméstica, o que foi confirmado neste experimento. Mas os autores relataram que o controle da mosca doméstica, por meio de lâmpadas ultravioletas não foi eficiente, uma vez que apenas $58 \%$ do total de moscas liberadas foram atraidas por todas as lâmpadas utilizadas nos testes. Neste trabalho observou-se que deixando-se as lâmpadas ligadas por uma hora, atrairam $62 \%$ do total de moscas liberadas. Vários outros autores também discutiram o uso deste tipo de lâmpada em diferentes armadilhas para captura da mosca doméstica. Segundo Morgan \& Pickens (1968) a lâmpada com luz ultravioleta foi uma das mais atrativas para mosca doméstica. Resultados similares foram obtidos por Pickens et al. (1969) em estábulos, onde eles obtiveram os melhores resultados com a armadilha luminosa a $2 \mathrm{~m}$ de altura e verificaram que os machos foram mais 
Tabela 1. Número e percentagem média ( $\pm \mathrm{EP})$ de Musca domestica atraidas por lâmpadas de diferentes comprimentos de onda associado com e sem a presença de saco plástico transparente contendo água com testador de luzes em uma sala mantida no escuro.

\begin{tabular}{lcccc}
\hline Tipo de lâmpada & Saco plástico com água & $\%$ & Sem saco plástico & $\%$ \\
\hline BL - BL & 79 & $39,5 \pm 4,49 \mathrm{~b}^{1}$ & 159 & $37,2 \pm 8,61 \mathrm{~b}$ \\
BL - BLB & 63 & $31,5 \pm 5,96 \mathrm{a}$ & 152 & $35,5 \pm 9,58 \mathrm{~b}$ \\
BLB - BLB & 58 & $29,0 \pm 2,35 \mathrm{a}$ & 117 & $27,3 \pm 7,58 \mathrm{a}$ \\
\hline Total & 200 & $31,9 \pm 9,09 \mathrm{~A}^{1}$ & 428 & $68,1 \pm 14,15 \mathrm{~B}$ \\
\hline
\end{tabular}

${ }^{1}$ Médias seguidas de mesma letra minúscula nas colunas ou maiúscula na linha, não diferem entre si pelo teste de Duncan $(\mathrm{P} \leq 0,05)$.

atraídos pela lâmpada BL.

No presente experimento observou-se que quando duas lâmpadas BL estavam alinhadas em sentidos opostos no testador de luz, a coleta de moscas foi maior do que quando existiam duas lâmpadas BLB em sentidos opostos ou uma lâmpada BL alinhada com uma BLB (Tabela 1). Assim, comparações realizadas por Pickens et al. (1969) e Pickens \& Thimijan (1986) entre bulbos fluorescentes com o tipo de luz negra (BL) e bulbos com luz negra azul (BLB) tem demonstrado que os bulbos BL são significativamente mais atrativos para mosca doméstica, do que os bulbos BLB para mesmo tamanho, forma e voltagem. Tem sido verificado que a

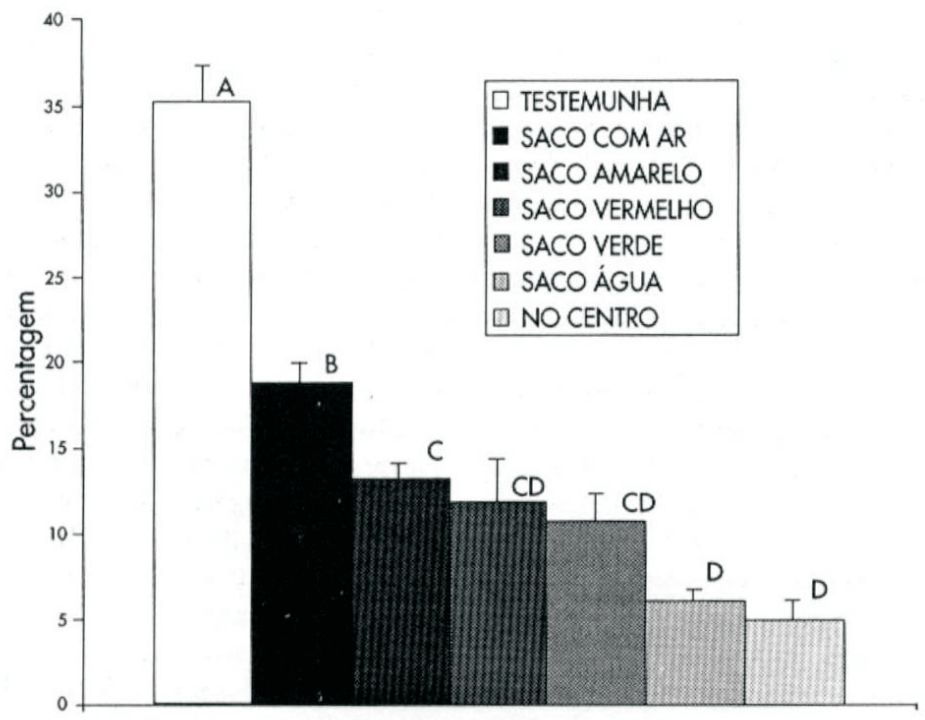

Tratamentos

Figura 1. Percentagem média ( \pm EP) do número de Musca domestica coletadas em quatro liberações com o testador de luz nos diferentes tratamentos a campo. Médias seguidas da mesma letra não diferem entre si, pelo teste de Duncan $(\mathrm{P} \leq 0,05)$. 
combinação de dois tipos de bulbos proporciona um incremento na proporção do ultravioleta para radiação de onda longa, sendo percebida pelas moscas como sendo diferente em cor quando comparada somente à fonte de radiação BL podendo, portanto, diferir na atratividade. Assim Pickens (1989) realizou um trabalho onde utilizou simultaneamente as lâmpadas BL e BLB e verificou que as combinações das duas lâmpadas não foram mais atraentes do que a lâmpada BL isoladamente.

No experimento de campo foi observado que a testemunha diferiu de todos os tratamentos (Fig. 1), tendo sido coletado nela o maior número de moscas $(35,2 \%)$. O tratamento com saco plástico transparente contendo somente ar apresentou valor intermediário $(18,6 \%)$, também diferindo dos de coleta $(5,9 \%)$, diferindo significativamente da maioria dos tratamentos, com exceção dos sacos plásticos transparentes contendo água de cor verde e vermelha. Segundo trabalhos realizados por Burg \& Axtell (1984) em aviários, as armadilhas pintadas com a cor amarela foram as que coletaram o maior número de moscas, seguida pelas cores vermelha e verde, em parte observado neste experimento.

Nos experimentos em ambiente fechado com caixas contendo Moscafim no seu interior, o saco plástico transparente com água de cor amarela, após duas horas da liberação capturou $10,2 \%$ das moscas e $35,7 \%$ após 24 h. Já a testemunha coletou $23,8 \%$ e $43,5 \%$, respectivamente (Tabela 2). Das cores, a amarela foi a cor mais atrativa para as moscas. A eficiência de repulsão das moscas foi de

Tabela 2. Percentagem média ( \pm EP) de Musca domestica atraídas por Moscafim em caixas em ambiente fechado após quatro liberações e avaliadas em dois horários de contagem utilizando como repelente saco plástico transparente contendo água, água colorida e um espelho.

\begin{tabular}{lccccc}
\hline Cores & Horário & \multicolumn{4}{c}{$\%$ de moscas coletadas } \\
\cline { 2 - 5 } & horas & Tratamento & Saco água & Testemunha & No chão \\
\hline Amarela & 2 & $10,2 \pm 1,99$ & $8,3 \pm 2,45$ & $23,8 \pm 4,18$ & $1,7 \pm 0,32$ \\
& 24 & $35,7 \pm 4,07$ & $18,9 \pm 3,97$ & $43,5 \pm 5,12$ & $1,9 \pm 0,39$ \\
& $E^{1}(\%)$ & 18,1 & 56,6 & & \\
Vermelha & 2 & $7,1 \pm 1,11$ & $8,2 \pm 1,15$ & $29,0 \pm 2,83$ & $0,7 \pm 0,02$ \\
& 24 & $16 \pm 2,02$ & $15,2 \pm 1,76$ & $67,3 \pm 8,79$ & $1,5 \pm 0,45$ \\
Verde & E $(\%)$ & 76,2 & 77,3 & & \\
& 2 & $5,2 \pm 0,89$ & $3,0 \pm 0,35$ & $24,0 \pm 3,29$ & $2,2 \pm 0,09$ \\
& 24 & $12,2 \pm 3,56$ & $10,2 \pm 2,64$ & $74,0 \pm 9,01$ & $3,6 \pm 0,61$ \\
Espelho & E $(\%)$ & 83,6 & 86,2 & & \\
& 2 & $14,9 \pm 1,04$ & $5,3 \pm 2,01$ & $28,9 \pm 5,65$ & $5,9 \pm 0,75$ \\
& 24 & $21,1 \pm 3,04$ & $7,4 \pm 1,79$ & $68,0 \pm 6,18$ & $3,4 \pm 0,63$ \\
& $\mathrm{E}(\%)$ & 68,9 & 89,0 & & \\
\hline
\end{tabular}

${ }^{1}$ Eficiência em repelir as moscas, segundo a fórmula de Abbott.

demais. Já os sacos plásticos contendo água colorida não diferiram entre si, mas a cor amarela diferiu dos demais tratamentos. Por outro lado, o saco plástico transparente contendo água apresentou os menores valores
$18,1 \%$ no tratamento com água amarela contra $56,6 \%$ no tratamento com saco plástico transparente com água. Isto demonstra que o saco plástico contendo água amarela foi a cor mais atrativa. Foi encontrado um grande 
número de moscas mortas, após 24 h, dentro da caixa onde se colocou o saco plástico contendo água de cor amarela, com valores próximos aos da testemunha, em decorrência do inseticida no Moscafim.

No teste do saco plástico transparente com água de cor vermelha coletou-se 7,1 e $16 \%$ dos indivíduos, nas contagens realizadas $2 \mathrm{~h}$ e 24 h após a liberação das moscas, respectivamente. A eficiência em repelir as moscas chegou a $76,2 \%$, com uma baixa mortalidade de moscas dentro da caixa (Tabela 2). Já na testemunha para o mesmo intervalo de tempo foram coletadas 29 e $67,3 \%$, respectivamente. A eficiência de repulsão das moscas no tratamento com saco plástico transparente contendo água foi de $77,3 \%$, sendo este valor bastante próximo ao da cor vermelha. A cor verde foi a que mais repeliu quando comparada ao saco plástico com água onde se obteve $3 \%$ na avaliação após duas horas e 10,2\% após $24 \mathrm{~h}$ da liberação (Tabela 2). Apresentou a maior eficiência do experimento atingindo 83,6\% contra $86,2 \%$ para o saco plástico transparente contendo água.

No experimento utilizando espelho, observou-se que após $2 \mathrm{~h}$ a coleta foi de $14,9 \%$ e após 24 h, 21,1\% das moscas liberadas (Tabela 2). A eficiência de repulsão dos insetos foi de $68,9 \%$, apresentando eficiência intermediária entre a cor amarela e as cores vermelha e verde. Já na testemunha observouse 28,9 e $68 \%$, respectivamente. A eficiência do saco plástico transparente com água foi de $89 \%$, constituindo-se no maior efeito de repulsão observado no experimento.

Os dados demonstram que o saco plástico transparente contendo água repeliu a mosca doméstica, principalmente nos experimentos com a incidência de luz em todas as direções no saco plástico, provavelmente devido ao efeito da refração da luz incidente sobre o saco plástico contendo água que atuou como um prisma. Diante dos resultados positivos tornase importante pesquisar o número de sacos plásticos contendo água a serem usados por área para garantir uma efetiva ação de repulsão da mosca doméstica, bem como verificar qual a quantidade de luz necessária para a eficiente repelência das moscas. Além disto, devem ser aprofundados os estudos em relação a influência do sexo, idade e nutrição da mosca doméstica na repelência pelo saco plástico transparente contendo água, uma vez que existem dados na literatura indicando a influência desses fatores em relação a experimentos realizados com armadilhas luminosas.

\section{Agradecimentos}

Os autores agradecem ao Prof. Dr. Sinval Silveira Neto pelo empréstimo dos equipamentos utilizados nos testes com luz e ao Prof. Dr. Evoneo Berti $\mathrm{F}^{\circ}$ pelo fornecimento do material biológico. Ao Prof. Dr. Alci E. Loeck pelas sugestões na elaboração do artigo.

\section{Literatura Citada}

Botelho, P.S.M., S. Silveira Neto, L.A.B. de Salles, D. Barbin \& C.G. Borges. 1973. Teste de atração de Musca domestica L. com luzes de diferentes comprimentos de onda. O Solo 65: 42-45.

Burg, J.C. \& R.C. Axtell. 1984. Monitoring house fly, Musca domestica (Diptera: Muscidae) in caged-layer poultry houses using a baited jug-trap. Environ. Entomol. 13: 1083-1090.

Deay, H.O. \& J.G. Taylor. 1962. Response of the house fly, Musca domestica L., to eletric lamps. Ind. Acad. Sci. 72: 161166.

Guimarães, J.H. 1985. Moscas sinantrópicas. Perspectivas de manejo integrado em aviários no Estado de São Paulo. Agroquímica 28: 10-15.

Mello, E.J.R. \& A. Pigatti. 1961. Resistência da Musca domestica (L.) e das larvas de Culex pipiens fatigans (Wied.) ao DDT e ao isômero gama do 
BHC, em São Paulo. Arq. Inst. Biol. 28: 25-34.

Morgan, N.O. \& L.G. Pickens. 1968. Influence of air temperature on the attractiveness of electric lamps to house flies. J. Econ. Entomol. 61: 1257-1259.

Nakano, O., S. Silveira Neto, S. \& R.A. Zucchi. 1981. Entomologia econômica. Piracicaba, Livroceres, 314p.

Pickens, L.G. 1989. Relative attractiveness of paired BL and BLB fluorescent bulbs of house and stable flies (Diptera: Muscidae). J. Econ. Entomol. 82: 535538.

Pickens, L.G. \& R.W. Thimijan. 1986. Design parameters that affect the performance of UV-emitting traps in attracting house flies (Diptera: Muscidae). J. Econ. Entomol. 79: 10031009 .
Pickens, L.G., N.O. Morgan \& R.W. Thimijan. 1969. House fly response to fluorescent lamps: Influenced by fly age and nutrition, air temperature, and position of lamps. J. Econ. Entomol. 62: 536-539.

Rutz, D.A., G.A. Scoles \& G.G. Howser. 1988. Evaluation of fly electrocuting black light devices in caged-layer poultry facilities. Poultry Sci. 67: 871-877.

Suplicy, N., F.E. Guthrie \& W.C. Dauterman. 1972. Toxicity of a series of dimethoate anologues to resistant and susceptible house flies. J. Econ. Entomol. 65: $1585-1587$.

Thimijan, R.W., L.G. Pickens \& N.O. Morgan. 1970. A trap for house flies. J. Econ. Entomol. 63: 1030-1031.

Recebido em 30/04/96. Aceito em 12/09/97. 